\title{
Thoracic Dystrophy
}

\author{
N. D. BARNES, D. HULL, and J. S. SYMONS \\ From The Hospital for Sick Children, Great Ormond Street, London; and Battle Hospital, Reading
}

In 1954 Jeune et al. reported the clinical details of a girl with a chondrodystrophy principally affecting the thoracic cage. The child suffered recurrent respiratory infections and died at 18 months as a consequence of the chest deformity. Her brother, who showed identical skeletal abnormalities, died at 8 months of a trivial respiratory infection (Jeune, Béraud, and Carron, 1955). Jeune and his colleagues proposed the name 'dystrophie thoracique asphyxiante de caractère familial' for the condition. A further 30 children showing similar features have been described from France, Italy, America, and Israel. This report concerns 2 infants who died of asphyxia primarily due to a small chest cage. The mother of one has similar, though much less severe, skeletal abnormalities.

\section{Case Reports}

Case 1. The first child, a boy, of unrelated parents, mother Austrian and father English. Hydramnios developed during pregnancy, but radiological examination did not reveal any fetal abnormality. He was delivered by elective caesarean section at 38 weeks' gestation because his mother's pelvis was severely contracted. His birthweight was $2.5 \mathrm{~kg}$. At delivery he was blue and hypotonic and his very small thorax was immediately obvious. Spontaneous respiration was established within 5 minutes, but he remained deeply cyanosed and therefore his trachea was intubated and his lungs artificially ventilated with oxygen. One hour after birth he was able to maintain a satisfactory colour when nursed in an incubator with added oxygen. Over the following days his condition improved a little but he remained distressed with a rapid respiratory rate, and he could not be weaned from oxygen. During any disturbance, such as handling or feeding, he became acutely distressed and cyanosed; however, when he was fed by tube he gained weight satisfactorily. By the age of 6 weeks the cyanotic attacks had become progressively more severe, and he was transferred to The Hospital for Sick Children, Great Ormond Street.

On examination it was clear that the reduced chest capacity was the major factor contributing to his

Received June 25, 1968. respiratory difficulty. The thoracic cage was remarkably small in all dimensions, especially in its upper part which appeared almost cylindrical. The circumference at the level of the nipples was $28 \mathrm{~cm}$. which contrasted with a head circumference of $37.5 \mathrm{~cm}$. and an abdominal girth at the umbilicus of $39 \mathrm{~cm}$. In spite of extreme respiratory efforts and marked recession of the intercostal and subcostal tissues, the ribs and sternum remained absolutely fixed, his breathing being thus entirely abdominal. On auscultation bilateral râles were heard. The abdomen was prominent and depression of the diaphragm was indicated by the fact that the liver and spleen, though not enlarged, were easily palpable $7 \mathrm{~cm}$. and $2 \mathrm{~cm}$. below the costal margins. The skull, limbs, hands, and feet were of normal proportions. There was a small sacral dimple but the spine was clinically normal. No cardiac murmur or other abnormality was noted.

To gain a more accurate estimation of the infant's breathing capacity his ventilation was measured with a spirometer connected to a face mask, and the intrathoracic pressure was simultaneously recorded from an oesophageal tube. Part of the record obtained is shown in Fig. 1. During quiet respiration the tidal volume was $10 \mathrm{ml}$. and the rate 60 per minute, giving a minute volume of $600 \mathrm{ml}$. To achieve this, however, large swings of intrathoracic pressure, approximately $25 \mathrm{~cm} . \mathrm{H}_{2} \mathrm{O}$, were required. Thus even during quiet respiration the infant was performing considerable respiratory work. When he attempted to cry, high pressure swings were observed, but these were paradoxically associated with a reduction in tidal volume, confirming the clinical observation that crying increased the cyanosis.

Chest $x$-ray (Fig. 2) showed the very small thorax; the upper ribs were horizontal and all the ribs short, with expanded costochondral junctions. The clavicles were high, giving an appearance which has been likened to the handlebars of a bicycle. The heart appeared large in relation to the thorax, but there was no absolute enlargement. The limbs were radiologically normal, with no evidence of achondroplasia, and the pelvis showed no abnormality. Other investigations included $\mathrm{Hb} 11.6$ g./100 ml.; WBC 21,000/cu. mm. (neutrophils $42 \%$; lymphocytes $56 \%$; monocytes $2 \%$ ); urea $43 \mathrm{mg}$. $100 \mathrm{ml}$.; sodium $134 \mathrm{mEq} / 1$; ; chloride $95 \mathrm{mEq} / 1$.; $p \mathrm{H} \mathrm{7.18} ; \mathrm{PCO}_{2} 105 \mathrm{~mm}$. $\mathrm{Hg}$; standard $\mathrm{HCO}_{3}^{-} 27.5$ $\mathrm{mEq} / 1$; base excess $+4 \mathrm{mEq} / 1$. ECG was within normal limits. 


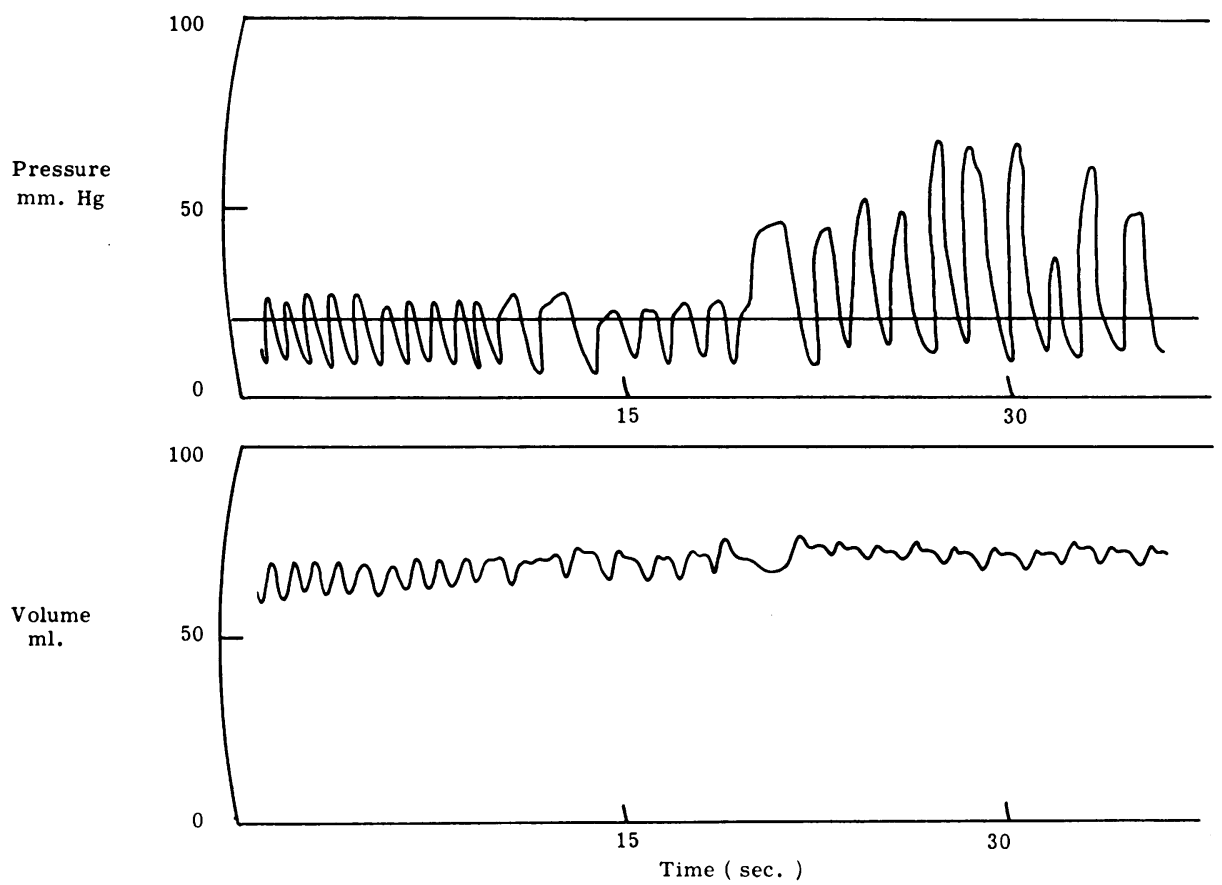

FIG. 1.-Case 1. Simultaneous recording of oesophageal pressure (upper trace) and tidal ventilation (lower trace). The record demonstrates the reduction in tidal exchange in spite of increased intrathoracic pressure changes when the baby attempted to cry, starting at about 17 sec. on the time scale.

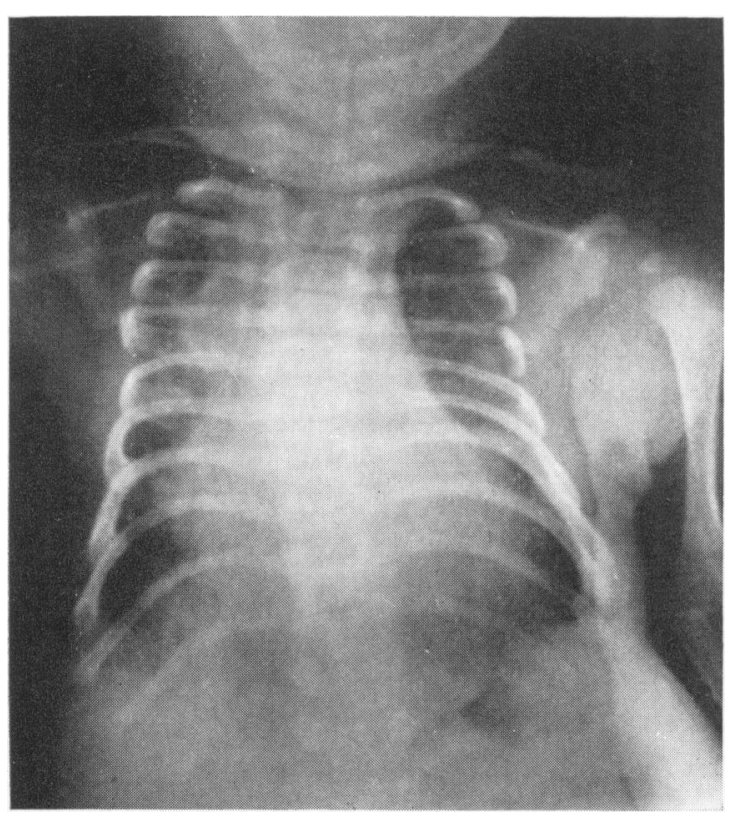

Fig. 2.-Case 1. Age 6 weeks. Chest x-ray showing small thorax and abnormally shaped ribs.
It was clear that his small, fixed chest would make artificial ventilation difficult or impossible. An immediate surgical attempt to enlarge the chest capacity was considered but rejected, chiefly on the assumption, which later proved wrong, that the lungs would be hypoplastic. He was managed conservatively with oxygen and antibiotics, but 36 hours after admission his condition deteriorated rapidly and his ventilation was clearly inadequate. Tracheal intubation was achieved with difficulty; an endotracheal tube passed easily through the cords but only a very fine tube could be advanced beyond an apparent constriction in the upper trachea. Satisfactory manual ventilation proved impossible. Even high pressures (up to $80 \mathrm{~cm}$. water) failed to move the chest, or to achieve an adequate respiratory exchange, and he died.

Necropsy. The relevant findings were confined to the skeleton and the respiratory tract. The thorax was extremely small and oddly shaped, as already described. Measurement of lung volume taken via the trachea, with the diaphragm and chest wall intact, indicated that the total lung volume did not exceed $30 \mathrm{ml}$. and that high pressures were necessary to inflate the lungs in situ. The costochondral junctions were widely expanded. Histologically they showed marked dystrophic changes (Fig 3), with failure of enchondral ossification, columns of irregular uncalcified cartilage extending into the trabeculae. The rest of the skeleton, 


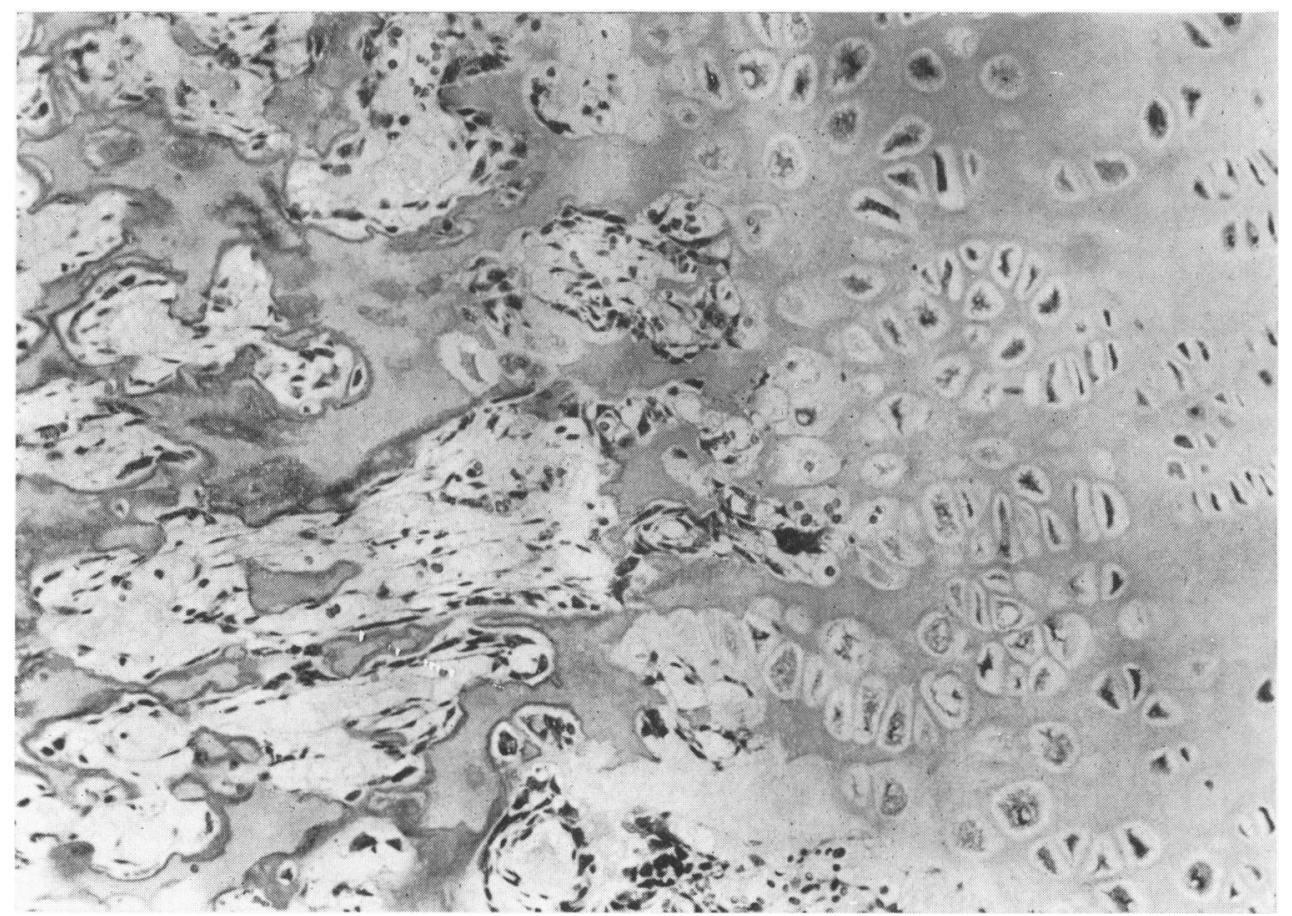

Fig. 3.-Case 1. Histological appearance of costochondral junction showing dystrophic changes (see text). (H. and E. $\times$ 135.)

including the long bones, were normal macroscopically, and histological examination of a femur and a clavicle showed no abnormality.

The larynx was small and the laryngeal cartilages formed a 'funnel' below the vocal cords, causing the first part of the trachea below the level of the cricoid cartilage to be narrowed. The trachea and main bronchi were otherwise normal. There was no sign of infection. The right lung weighed $24 \mathrm{~g}$. and the left $19 \mathrm{~g}$. (total $43 \mathrm{~g}$., normal $60 \mathrm{~g}$.). The right lung was inflated, and the pressure volume relation is shown in Fig. 4. This is probably within the normal range for his age. Histologically the lungs were normal.

Mother of Case 1. During her pregnancy this mother was noted to have a small chest and contracted pelvis. The fact that she also had a small larynx became apparent when she was given an anaesthetic. These abnormalities had caused no disability in adult life. However, though there is no record of respiratory difficulty in the neonatal period, from the age of 3 months to 1 year she suffered from recurrent respiratory infections, and at this time her weight fell below the third centile. She was also under the care of an orthopaedic surgeon, as her walking was delayed and her gait abnormal.

Her chest is small in proportion to her height; radiologically the subcostal angle is wide, the ribs are horizontal, and there is bilateral pleural thickening.
The costochondral junctions appear normal. The liver and spleen are not enlarged but are easily palpable below the costal margins. The pelvis is severely

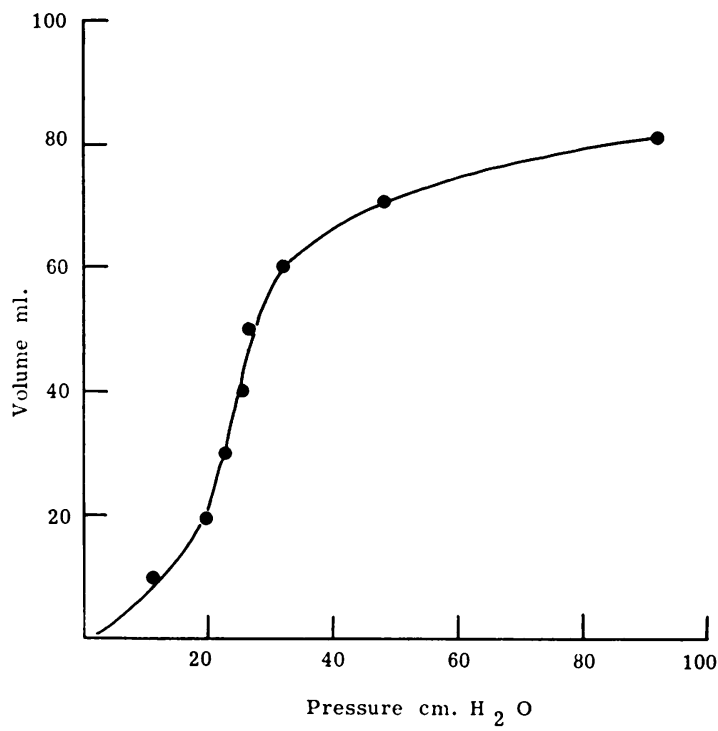

FIG. 4.-Case 1. Inflation pressure volume relation on the isolated right lung. This is probably normal. 
contracted (true conjugate $7.0 \mathrm{~cm}$.) and shows radiological features suggestive of achondroplasia, with very small, 'squared' iliac bones and deep, narrow sciatic notches. The skull, spine, and long bones are normal. Respiratory function tests show reduced lung volumes. All chest measurements are much reduced compared with those of her normal sister who is of comparable height and is her only sib. Her parents are both normal.

Case 2. The second child, a girl, of healthy Jewish parents who were first cousins. Their first child, also a girl, was normal, and there was no family history of any similar disorder. She was born by normal delivery after a surgical induction at 43 weeks' gestation; her birthweight was $2.9 \mathrm{~kg}$. Her narrow, fixed chest was obvious, and because of persistent cyanosis she was

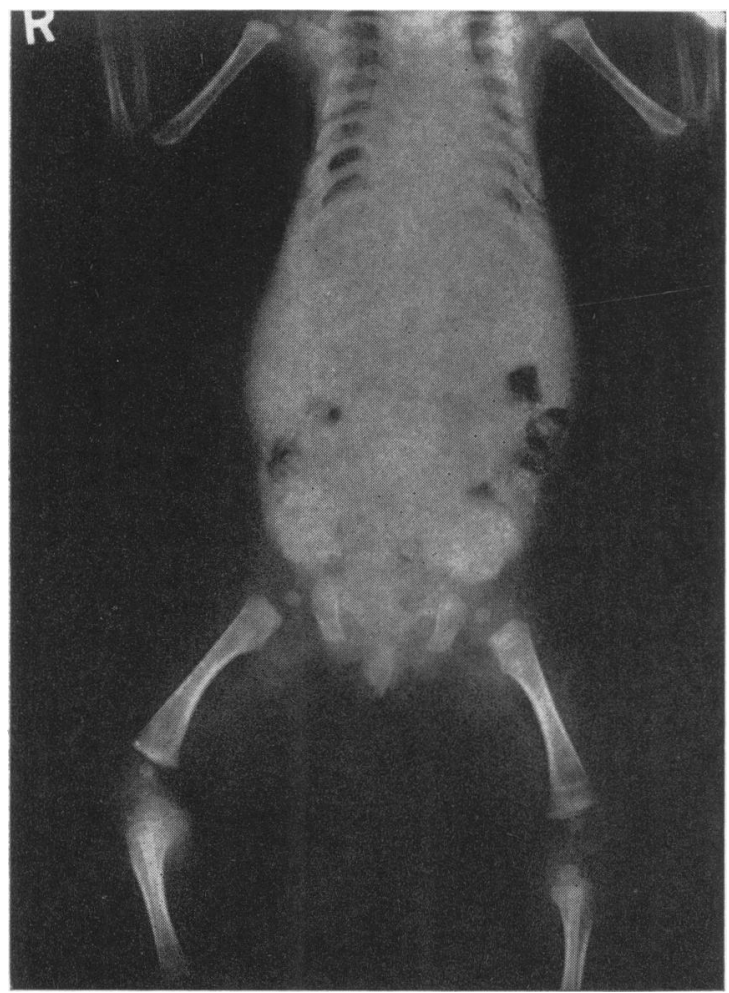

Fig. 5.-Case 2. Age 4 months. Whole body x-ray showing changes in ribs, pelvis, and long bones (see text).

nursed in an incubator with added oxygen for the first two months of life. There was no evidence of cardiac disease. Her limbs were noted to be a little short, but she did not show the features of achondroplasia. She improved a little, was weaned from oxygen, and allowed home. She was readmitted, however, at the age of 4 months, with an exacerbation of her respiratory difficulty, and spent a further 3 months in hospital. Radiological examination at this time (Fig. 5) showed her very small chest with short stumpy ribs and expanded

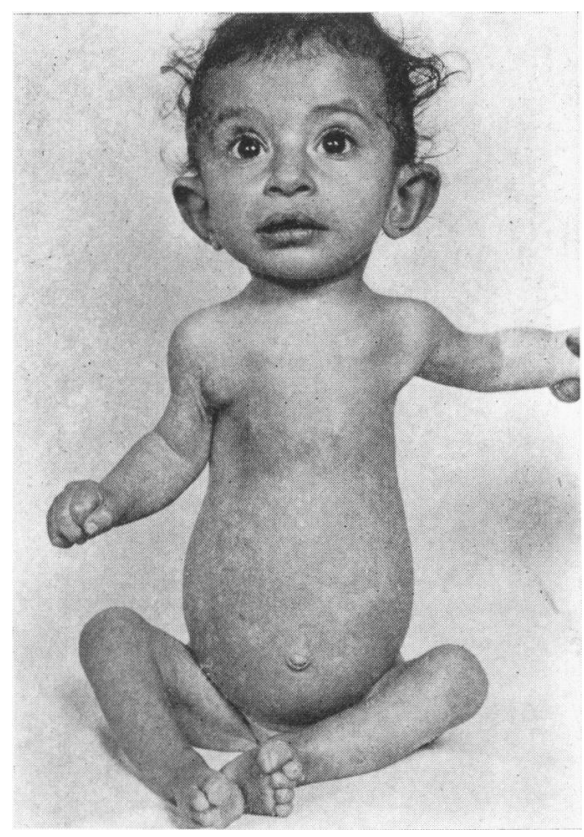

FIG. 6.-Case 2. Age 1 year.

costochondral junctions. The long bones were short and wide especially at the metaphyses, and showed some irregularity of the epiphyses. The pelvis showed squaring of the iliac bones, narrow sciatic notches, and irregular horizontal acetabular roofs. The glenoid cavities were also irregular. She improved a little and was allowed home, though her growth and physical development were severely retarded. At the age of 1 year she developed a cough, her condition deteriorated rapidly, and she was admitted to The Hospital for Sick Children, Great Ormond Street.

On admission, aged 1 year, she had extreme respiratory distress, cyanosis, tachypnoea, and intercostal and subcostal recession. She was very small for her age (weight $4.3 \mathrm{~kg}$; height $63 \mathrm{~cm}$.), but her proportions were normal except for her small and fixed chest (Fig. 6). Her head circumference measured $39.5 \mathrm{~cm}$., her chest at the level of the nipples $32.5 \mathrm{~cm}$., and abdomen at the level of the umbilicus $37.5 \mathrm{~cm}$. On auscultation, râles were heard in both lungs. The pulse rate was $180 / \mathrm{min}$., the heart was clinically normal. The abdomen was prominent, the liver palpable $2 \mathrm{~cm}$. and the spleen $3 \mathrm{~cm}$. below the costal margins. $\mathrm{Hb}$ $13 \cdot 7$ g. $/ 100 \mathrm{ml}$; WBC $12,400 / \mathrm{cu}$. mm. (36\% neutrophils; $59 \%$ lymphocytes; $5 \%$ eosinophils). Serum urea, sodium, potassium, chloride, calcium, inorganic phosphate, and alkaline phosphatase were normal, bicarbonate $25.4 \mathrm{mM} / 1$. ECG showed some right ventricular preponderance with $\mathrm{P}$ pulmonale. Chest $x$-ray (Fig. 7) showed little improvement in the thoracic deformity. Screening confirmed the clinical impression that the chest wall was fixed and breathing entirely diaphrag- 

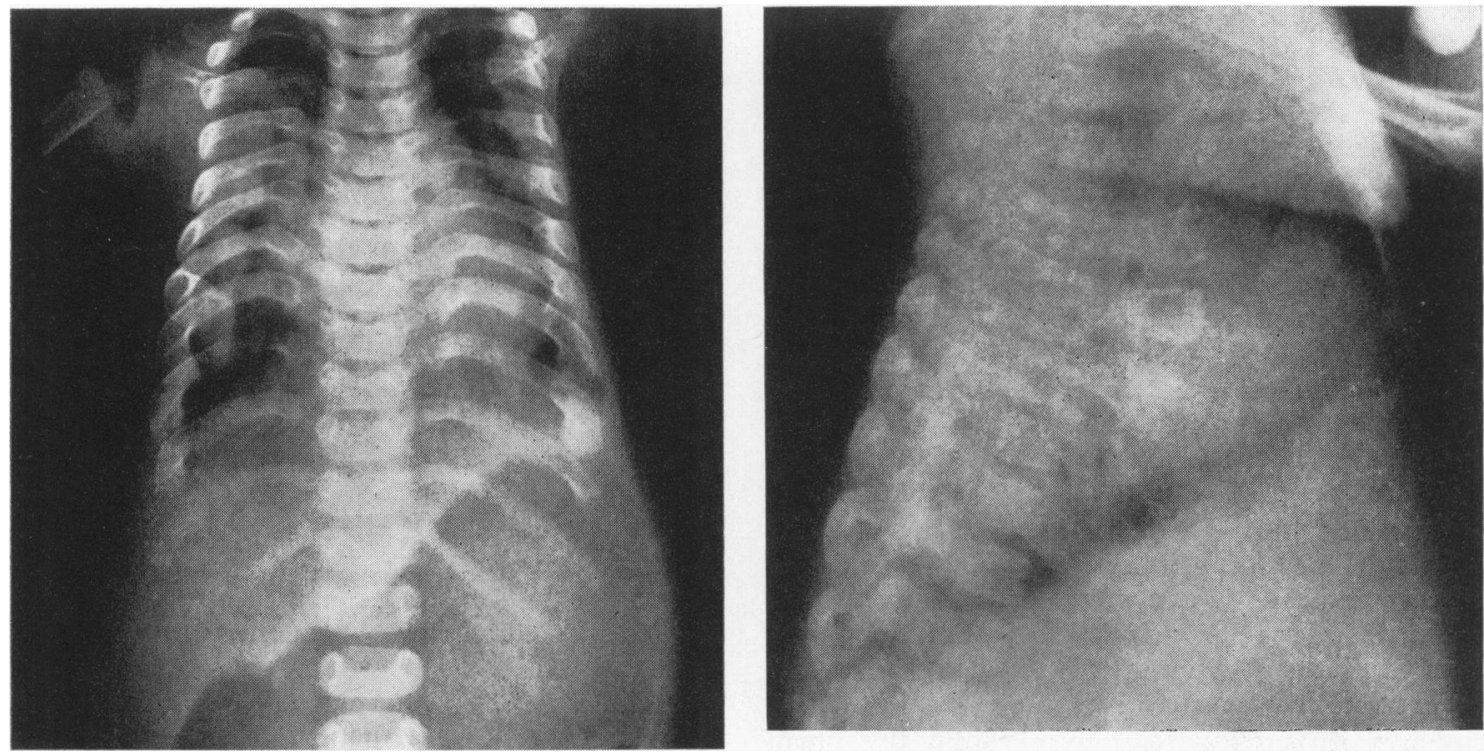

Fig. 7.-Case 2. Age 1 year. (a) Postero-anterior and (b) lateral chest x-ray. Abnormality of ribs, and small thorax as in Fig. 5.

matic. The long bones were now radiologically normal, but the bones of the metatarsus, metacarpus, and phalanges were short and showed a pyriform deformity of some epiphyses.

She was given antibiotics, digitalized, and nursed in a high oxygen concentration; she improved at first, but one month after admission she deteriorated and died. Permission for necropsy was refused.

\section{Discussion}

The chondrodystrophies are a heterogeneous group of conditions which have in common a failure of enchondral ossification. Satisfactory classification is made difficult by the wide variation in expression, the frequent apparent disparity between clinical, radiological, pathological, and genetic findings, and, in most of these disorders, the lack of a known specific biochemical defect.

At least 31 cases of thoracic dystrophy (19 male, 12 female) have been described, and references to these reports are given below (Balocco, 1963; Balocco, and Zoratto, 1960; Centa and Piccinini, 1965; De Sario and Marchese, 1956; Fleury, Billiard, and Burtin, 1964; Fontan et al., 1965; Marchese and Balocco, 1964; Mazzola and Rivolta, 1965; Menichini and Vizzoni, 1966; Neimann et al., 1963; Pozzan, 1964; Saguì and Sagui, 1964). In addition, the case of a girl reported by Shapira et al. (1965) 'as incomplete regional achondroplasia (ilium and ribs)' appears to fall into the same group. The condition is probably a generalized chondrodystrophy, with the major changes being confined to the chest and pelvis.

The radiological appearance is characteristic. The chest cage is narrow, especially in its upper part which, with the relative flaring of the lower ribs, accounts for the 'fetal' or 'bell' shape. The ribs are short and horizontal in position, their distal metaphyses are widened, and the costochondral junctions expanded and irregular. The clavicles are high. The heart may appear enlarged in relation to the size of the chest. The hypoplastic ribs result in a fixed chest of very small volume. The severity of the deformity, however, and of the consequent functional disability, is variable. Thus, of the 32 patients, 19 died of asphyxia, with or without superadded infection, at ages ranging from 1 day to 13 months, but 13 were alive and asymptomatic at ages from 15 days to 11 years.

The occurrence of extrathoracic abnormalities is also variable. The pelvis was noted to be abnormal in 24 cases, the changes generally resembling those of achondroplasia with short squared iliac bones, deep sciatic notches, horizontal acetabula, and irregular ossification margins. In 11 there were minor dystrophic changes of other flat bones, in most cases irregularity of the glenoid fossa. In 21 cases the long bones showed some abnormality, tending to be a little short and wide, especially 
at the metaphyses, with some irregularity of the epiphyses. The metacarpals and metatarsals were similarly affected in 7 cases.

Other features of note include a lacunar skull in 2 cases, clubbed feet in 1 , polydactyly in 4 , dental anomalies in 3, hypoplasia of the abdominal muscles in 3, and hypoplastic nails and teeth in 1 . No abnormality of the spine was noted.

Histological findings were reported in 7 cases: these confirmed the chondrodystrophic changes of the costochondral junctions, and in one case similar though less severe changes were noted in the femoral epiphyses. In 2 cases there were degenerative changes of the anterior horn cells of the thoracic spinal cord.

Nineteen patients had one or more sibs affected, and another 3 sibs, who were probably affected, had died previously. There were 18 normal sibs. One child was the product of a first cousin marriage, and this child also had a maternal uncle and aunt who showed similar features.

Thus it is clear that even within this small group of patients there is considerable variation in the clinical, radiological, pathological, and genetic features, and it is possible that more than one entity is represented. It is interesting to note, for instance, that those cases that show polydactyly have all survived, and may thus be less severely affected and perhaps genetically distinct. It is most probable that the condition is inherited as an autosomal recessive. The apparent high incidence among sibs is probably due to selection and the minor changes in the mother of Case 1 may represent a heterozygous state. The changes in an uncle and aunt of an index case are difficult to explain, but it is possible that this family was highly inbred (Shapira et al., 1965). However, dominant inheritance with variable expression cannot be ruled out.

It is clear that none of the cases can be satisfactorily classified with any of the more clearly defined chondrodystrophies. Maroteaux and Savart (1964) and Hanissian, Riggs, and Thomas (1967) have suggested that the condition may be a variant of the Ellis-Van Creveld syndrome, in which a similar chest deformity has been described (Smith and Hand, 1958). Polydactyly, dystrophic changes in the peripheral long bones, and poor development of the nails and teeth, features of the Ellis-Van Creveld syndrome, may be present in patients with the condition under discussion, but infrequently, while congenital heart disease and the characteristic changes in the carpus and tibial plateau in the Ellis-Van Creveld syndrome have not been described. In achondroplasia there may be similar dystrophic changes in the ribs, with gross reduction of the chest capacity and a comparable functional disability. The changes in the pelvis are also indistinguishable from those of achondroplasia, but the limbs, spine, and skull do not show the characteristic features. Thus, until it is possible to devise a more satisfactory classification, it seems justified to group together those cases with a chondrodystrophy which chiefly affects the thoracic cage. Since neither asphyxia nor presentation in the neonatal period are necessary features, the present designation 'asphyxiating thoracic dystrophy of the newborn' is probably better contracted to 'thoracic dystrophy'.

The two cases we report demonstrate several features of interest. Case 2 provides the second example of the condition occurring in the child of first cousins, which lends support to the probability of recessive inheritance. Her $x$-rays over a sixmonth period show the tendency already noted by several authors for the radiological appearances to improve. In this patient this was chiefly evident in the limbs, but in those cases where serial $x$-rays over several years are available, there has also been remarkable improvement in the chest (Pirnar and Neuhauser, 1966).

Case 1 and his mother provide the first demonstration that the condition can occur in parent and child and emphasize the variation in severity. In this infant the thoracic deformity was sufficiently severe to be the direct cause of death at 7 weeks, whereas in his mother it was so mild that it has caused no functional disability since the first year of life. The chondrodystrophic changes were also remarkably specific. Apart from the pelvis in the mother of Case 1, there was no evidence of involvement of bones other than the ribs. The only associated abnormality was that of the larynx in both mother and child.

The disorder of respiratory mechanics is clearly due to the greatly reduced thoracic volume. The diaphragm is depressed and, since the chest wall is fixed, an adequate tidal exchange can only be achieved by powerful diaphragmatic efforts. Theoretically, it might have been better to have attempted ventilation of this infant by applying negative rather than positive pressure to the endotracheal tube. When he attempted to cry he produced very high intrathoracic pressures, but this caused a further reduction in tidal volume, probably due to collapse of the airways.

It is clear that slow growth of the ribs does occur, and it seems probable that even the most severely affected children may develop adequate respiratory function if they can be tided over the critical period 
until they develop an adequate chest volume. The observation that the lungs are not hypoplastic and are able to expand to a satisfactory volume gives added justification to surgical attempts to relieve the constriction of the thoracic cage. This has been attempted in 2 children. In one 8-month-old girl 3 right and 4 left ribs were resected; there was a temporary improvement, but she died of pneumonia 8 weeks after the operation (Razzi, Rosso, and Durand, 1965). In another 6-month-old girl the costochondral junctions only of 3 right and 4 left ribs were resected, but again the patient died of pneumonia after operation (Durand et al., 1965). The most rational approach might be to split the sternum and fix it in this position with bone grafts or synthetic material. This could give a considerable increase in the total chest capacity without destroying the mechanical function of the thoracic cage in respiration. The prognosis for those who survive the early years appears to be good.

\section{Summary}

Thoracic dystrophy is a chondrodystrophy which chiefly affects the costochondral junctions and therefore the growth of the ribs, resulting in an extremely small and rigid chest cage. 32 infants with this condition have previously been described, of whom 20 died within the first 13 months of life as a result of the chest deformity.

Two further infants with the characteristic deformity are described. The mother of one showed similar but less severe skeletal abnormalities; the other is the child of a first cousin marriage. Both died of asphyxia. Physiological and pathological studies in one case suggest that it may be possible, surgically, to enlarge the chest enough to support life until further growth of the ribs occurs.

We are grateful to Dr. D. G. Cottom, Dr. P. R. Evans, and Dr. D. G. H. Stone for permission to report details of patients under their care; to our radiological colleagues
Dr. J. Sutcliffe and Dr. A. R. Chrispin, who recognized the condition in our first patient; and to Dr. C. Berry, who performed the post-mortem examination.

\section{REFERENCES}

Balocco, A. (1963). Ulteriore contributo sulla policondrodistrofia. Minerva pediat., 15, 309.

- and Zoratto, E. (1960). Considerazioni cliniche sudi un caso di policondrodistrofia. ibid., 12, 1618.

Centa, A., and Piccinini, A. (1965). La distrofia toracica asfissiante (di Jeune) nel neonato. Pathologica, 57, 233.

De Sario, P. N., and Marchese, G. S. (1956). Su un caso di distrofia encondrale poliepifisaria in un neonato con alterazione mortale della dinamica respiratoria. Minerva pediat., 8, 1415.

Durand, P., Mastragostino, S., Razzi, A., and Gimelli, F. A. (1965). $\mathrm{La}$ distrofia toracica asfissiante (malattia di Jeune) tentativo d'intervento chirurgico sulla gabbia toracica. ibid., 17, 1437.

Fleury, J., Billiard, J., and Burtin, P. (1964). Dystrophie thoracique asphyxiante. Arch. franc. Pédiat., 21, 465 .

Fontan, A., Guichard, R., Delorme, G., Barrin, J. J., and Auboin, B. (1965). Un case de dystrophie thoracique asphyxiante du nourrisson. Ann. Radiol., 8, No. Hors-Serie, 163.

Hanissian, A. S., Riggs, W. W., Jr., and Thomas, D. A. (1967). Infantile thoracic dystrophy-a variant of the Ellis-Van Creveld syndrome. $\mathcal{F}$. Pediat., 71, 855.

Jeune, M., Béraud, C., and Carron, R. (1955). Dystrophie thoracique asphyxiante de caractère familial. Arch. frans. Pédiat., 12, 886.

- Carron, R., Béraud, C., and Loaec, Y. (1954). Polychondrodystrophie avec blocage thoracique d'évolution fatale. Pédiatrie, 9,390

Marchese, G. S., and Balocco, A. (1964). Osteocondropatia embrionaria politopa con insufficienza respiratoria, 'di Jeune'. Minerva pediat., 16, 965.

Maroteaux, P., and Savart, P. (1964). La dystrophie thoracique asphyxiante. Étude radiologique et rapports avec le syndrome d'Ellis et Van Creveld. Ann. Radiol., 7, 332.

Mazzola, G., and Rivolta. S. (1965). Distrofia toracica asfissiante. Pediatria (Napoli), 73, 1123.

Menichini, G., and Vizzoni, L. (1966). La malattia di Jeune in eta neonatale. Riv. Clin. pediat., 78, 620.

Neimann, N., Manciaux, M., Rauber, G., Pernot, C., and Bretagnede-Kersauson, M. C. (1963). Dystrophie thoracique asphyxiante du nourrisson. Pédiatrie, 18, 387.

Pirnar, T., and Neuhauser, E. B. D. (1966). Asphyxiating thoracic dystrophy of the newborn. Amer. 7. Roentgenol., 98, 358.

Pozzan, M. (1964). Distrofia toracica asfissiante del lattante. Acta paediat. lat. (Reggio Emilia), $17,1$.

Razzi, A., Rosso, C., and Durand, P. (1965). Contributo anatomopatologico alla distrofia toracica asfissiante del lattante (malattia di Jeune) e considerazioni sull'utilità terapeutica dell'intervento chirurgico sulle coste. Minerva pediat., 17, 1823.

Sagui, G., and Sagui, L. (1964). Distrofia toracica asfissiante del lattante. Aggiorn. pediat., 15, 427.

Shapira, E., Fischel, E., Moses, S., and Levin, S. (1965). Syndrome of incomplete regional achondroplasia (ilium and ribs) with abdominal muscle dysplasia. Arch. Dis. Childh., 40, 694.

Smith, H. L., and Hand, A. M. (1958). Chondroectodermal dysplasia (Ellis-Van Creveld syndrome): report of two cases. Pediatrics, 21, 298. 